\title{
AN EVALUATION OF LOCAL AND GENERAL ANAESTHESIA FOR DIAGNOSTIC BRONCHOSCOPY*
}

\author{
H. Barrie Fairley, M.B., B S , F F A R C.S. *
}

THE subject of anaesthesia for bronchoscopy has been ventulated with great frequency and at considerable length for many years It is evident that there are many ways of performing this feat and that, since papers are still being written on the subject, 100 per cent success has yet to be achieved

This paper is based on work carried out, at the Brompton Hospital for Diseases of the Chest, London, England, on 275 diagnostic bronchoscopies, 145 of these patients received local and the remainder generdl anaesthesia.

It is proposed to present this subject under the following heacings (1) A discussion of the ideal anaesthetic conditions for bronchoscopy, (2) A report and discussion of the degree of success-or lack thereof-achieved by both local and general anaesthesia in the present series, (3) Suggestons as to how current methods of anaesthesia may be improved upon, in the not too distant future.

It is noted that the literature on this subject gives very few figures for certain aspects of this problem-especially patients' opinions, surgical facility and complication rates. It is hoped that, to some extent, this paper may fill the gap

\section{Ideal Anaesthetic Conditions}

As in other fields, a search is being made for that form of anaesthesia which will produce ideal operating conditions with a minımum of unpleasantness for the patient.

\section{A. Ideal Operating Conditons}

Relaxation of the jaw is an essentral in this procedure and it is necessary to be able, without trauma, to insert the bronchoscope between the vocal cords. However, two other necessities are open to discussion

(1) Respuratory movements. These permit the surgeon to observe two things (a) Vocal cord mobility-this is something which may be assessed separately by indirect laryngoscopy, $(b)$ The respiratory constrictive movements of the bronchial orfices, lack of which denotes pathology in the immediate vicinity Knowing that this lack of mobility is associated with recognizable increased local rigidity, not dependent upon respiration, most bronchoscopists are prepared to forego the opportunity to assess this point.

(2) Cough reflex It is important to prevent the patient coughing as a result of the urritation of the bronchoscope but he should be in control of his more bulky secretions and, more so, of any gross bleeding produced during the exam1nation Really extensive local anaesthesia abolishes the cough reflex but the

*Presented at the Annual Meeting, Canadian Anaesthetısts' Society, Mont Tremblant, P Q

- Department of Anaesthesia, Toronto General Hospital, lately, Registrar, Department of Anaesthesia, Brompton Hospital, London, England 
wakeful patient can still cough voluntarly as can the patient under general anaesthesia who has had no local anaesthesia and who can be wakened very quickly The majority of the patients under general anaesthesia in this series received such a sequence and its merits and demerits will be discussed later.

At this point, it should be stated that many very experienced bronchoscopists are most concerned at the difficulty of saving the life of the patient under general anaesthesia who suffers a massive haemorrhage owing, for instance, to inadvertent pulmonary artery puncture at biopsy. The resulting gush of blood is an extremely alarming sight but the situation is, by no means, irreversible. Dy]wyn Thomas (1), from Sully, reports that he has experienced such an incident under both types of anaesthesia and the increased difficulty of having a patient under a general anaesthetic was very troublesome. d'Abreu (2) recommends that, in the event of such a catastrophe, a Thompson bronchial blocker be inserted down the bronchoscope (which should have been kept in position) thus confining the haemorrhage to one lobe or lung

\section{B Degree of Risk}

The danger of haemorrhage has been mentioned Other points of more constant importance are

(1) Ventilation. Of necessity, many of the candidates for this examination will have gross pulmonary disease and no patient should be anaesthetized for bronchoscopy untl his chest plates have been examined by the anaesthetist. Fallure to be aware of the presence of a large fluid level in an empyema cavity with a bronchopleural fistula, for instance, could termmate in a senous emergency

Good spontaneous respiration, through a bronchoscope down which oxygen is flowing and which has several lateral orffices, should ensure adequate oxygenation and carbon dioxide elımmation Under local anaesthesia, this is usually the case Under general anaesthesia, it is unfortunate that spontaneous respiration, absent cough reflex and complete wakefulness withn a minute or two of the end of the examnation are difficult to acheve. One of these is usually sacrificed. It is felt that general anaesthesıa is only acceptable for bronchoscopy if the endoscopist can complete his task easily and if the patient is completely awake within a minute or two of the end of the examination The postoperative somnolent patient, locally anaesthetized, is in a most unsatisfactory condition to look after his secretions If the local has achieved its intended effect then, of necessity, a conscious effort will be necessary for expulsion of secretions Thus, local and general should not, in the author's opmion, be combined. In order to achieve the above requirements with drugs presently avallable, it is common-as in this series -to use a short-acting relaxant to the point of gross or complete dimmution of respiratory movements. It is felt that hypercarbia is the main risk of this technique, given hyperventilation with oxygen at the outset and an adequate flow of oxygen, delivered at carnal level during the examination. This is borne out, in respect to those with reasonable pulmonary function, in the very interesting report by Jooste (3) in which he described cases rendered apnoerc and not ventılated for 
considerable periods. In one example, he gives blood gas figures after thirty minutes' apnoea. At this time, the oxygen saturation was 103 per cent but the arterial $\mathrm{pH}$ was 6.97 , the carbon dioxide tension having risen to nearly three times normall There were no clinical symptoms or signs other than fifteen points rise in systolic blood pressure. He reminds us of the insufflation methods introduced by Meltzer and Auer, but points out that the very high flow of oxygen necessary to eliminate carbon dioxide is impracticable in this type of work This will be referred to again in the report of the cases under general anaesthesia. The introduction of a small catheter, through the glottis and down to the carina, prior to passing the bronchoscope alongside it, enables oxygen to be delivered at the optımum point This method is in use in many centres and was described by Cheatle and Chambers (4) in 1955 . Ventilation, in the apnoeic patient, may be assisted by routine manual compression of the anterior chest wall, and, in an emergency, by inserting a sawn-off endotracheal tube (connected to a rebreathing bag and oxygen supply) into the end of the bronchoscope. These methods of ventilation were used in this series and have been described elsewhere $(5,6)$. Herron (8) has described an adaptor which may be placed over the surgeon's end of the bronchoscope. This has a transparent window in it, occluding the end of the bronchoscope and enabling more adequate ventilation to be achieved as the examination continues. The window may be hinged back to permit passage of telescopes and forceps. In passing, it is worth stressing that the anoxic collapsed patient will have a lax glottis and inflation will be difficult owing to leak of gas-just as it is with an uncuffed endotracheal tube.

(2) Toxic reactions. The literature is scattered with reports of toxic reactions to local anaesthesia and, although those concerned now have an increased awareness of the maximum dosage of the relevant agents, fatalities stall occur. In the fourteen years prior to this seres, two deaths had occurred at the Brompton Hospital in association with bronchoscopy, both due to toxic reactions to local anaesthesia. In this series, one cardiac arrest occurred following amethocaine administration but this was reversed by prompt massage. In the fewer years that general anaesthesia has been in use at this hospital, no deaths had occurred up to the time of writing.

\section{Unpleasantness for the Patient}

No figures were found in the literature referring to the patient's opinion on which type of anaesthesia he would prefer after experience of one or both forms, although many authors suggest that general is usually preferable $(5,6,7)$. In this series, 145 patients recerved local anaesthesia. All our patients were asked, the next day, if they would rather have a general anaesthetic if the procedure had to be repeated. Of these, 69 said "yes" ( 47.6 per cent). Several more said they did not know, because they had never had a general anaesthetic. Of 130 patients given general anaesthesia, 120 said they would have the same again. The remaining ten had experienced local anaesthesia previously and, of these, nine were adamant that they would never have bronchoscopy done under local again (to the extent of wanting to know why they had not had a general anaesthetic previously!). The remaining patient (0.8\%) said he had had a nasty dream 
with the general anaesthetic (which he could not remember the next morning) and would rather have a local.

Thus, in this series, 476 per cent of those given locals would prefer a general next time and 0.8 per cent of those given general anaesthesia would prefer a local.

\section{Techniques}

(1) Local anaesthesia. It is not proposed to go into detail on the many methods and drugs used for this type of work except to say that 100 per cent efficiency ( 1 e. the patient so anaesthetzed that the bronchoscope may be slipped through the open glottis, an exammation and, if necessary, a biopsy completed and the bronchoscope withdrawn-all with no reaction, as can be achieved with general anaesthesia) is almost impossible to obtain without paying most meticulous attention to every detail of the procedure: initial premedication, supplementation of this intravenously, application of the local anaesthetic, and accompanying encouragement of the patient. From the time the patient arrives in the preparation room, to the time he is ready for bronchoscopy, at least twenty to thirty minutes will have elapsed. One must be prepared to reapply the local if the first application was inadequate. To do this one must either have a very large staff and appropriate sausage-machine administration, as in the one or two world-famous bronchoscopy clinics in the Unuted States, or one must have all the time in the world Under such curcumstances, nearly every anaesthetist will be 100 per cent successful. Unfortunately, where a row of bronchoscopies is to be done, such circumstances seldom preval and it appears that it matters little which technique of application of local anaesthesia one uses, provided one is well acquainted with one of them.

(2) General anaesthesia Very good descriptions of technique are in the literature $(9,5)$ The requirements of general anaesthesia for this examination have been outlined when discussing some of the risks involved. The technique used in this series will be described in association with the results achieved.

\section{Brompton Hospital Series}

The patıents in this series were in a specialıst thoracic hospital and displayed a wide range of pulmonary pathology. The distribution of types of case given local or general anaesthesia was very similar. Gross pathology existed in approximately equal numbers, in both groups.

Cases were assigned to one or other type of anaesthesia solely on the grounds of surgeon's preference, i.e certain surgeons were in the habit of bronchoscoping all cases under local Others were prepared to examine all cases under general anaesthesia, subject to the anaesthetsst's approval. Broadly speaking, patients were not assigned to one or other group, in this series, on the grounds of their pathology but contraindications to each form of anaesthesia wi.l be considered later.

Only certain aspects of the two groups bear comparison and it was decided that it would be unwise to bronchoscope alternate cases under local and general anaesthesia since it was noted, very early on, that the bronchoscopist accustomed 
to one type of anaesthesia was not necessarily adept and happy with the other type. Thus, an acknowledged expert at passing a bronchoscope under local anaesthesia-with a "tight" pharynx-was noticeably less dexterous when inserting the instrument through the lax oro-pharynx under general anaesthesia. It was considered sound to compare the figures for several surgeons, each using the method with which he was most familiar. Some of the cases were examined by registrars, whose dexterity had not become specialızed in relation to any one type of anaesthesia.

Two clinical features were considered a basis for comparison of the two groups, as a rough assessment of the extent of respuratory disability. These are shown in Table I. It will be seen that for practical purposes the two groups are very similar but it should be mentioned that, in some instances, the decision as to which group was correct for a given case was difficult-especially with regard to sputum volume.

TABLE I

\begin{tabular}{lcc}
\hline DYSPNOEA & L A & G A \\
\hline No dyspnoea & $61(421 \%)$ & $52(40 \%)$ \\
Dyspnoea on exertion & $76(524 \%)$ & $72(554 \%)$ \\
Dyspnoea at rest & $8(55 \%)$ & $6(46 \%)$ \\
SPUTUM & L A & G A \\
\hline Trace or less & $69(476 \%)$ & $71(546 \%)$ \\
Less than 2 oz. & $70(483 \%)$ & $54(416 \%)$ \\
2 oz and more & $6(41 \%)$ & $4(31 \%)$ \\
\hline
\end{tabular}

The age distribution in the two groups was even, being from 18 to 78 under local and 14 to 77 under general anaesthesia Younger patients, bronchoscoped under general anaesthesia, were not included.

\section{Difficulty in Instrumentation}

If the surgeon was unable to insert the bronchoscope at the first attempt and without hesitation, this was classed as difficulty. Thus, 39 of the cases with local anaesthesia (1.e, 269 per cent) proved difficult and 18 (i.e, 13.8 per cent) of those under general anaesthesia

\section{Length of Bronchoscopy}

Each examination was timed from the moment the surgeon advanced on the patient with the bronchoscope to the moment it was removed from the mouth. These times were grouped into three-minute periods and the results are shown in Table II. A higher percentage of cases under general anaesthesia was completed in nine minutes.

Thus, it is seen that, in this series, it was somewhat easier to pass a bronchoscope under general anaesthesia and the whole examination took less timeespecially when one considers the greater speed of induction of general, as 
TABLE II

\begin{tabular}{lrrcc}
\hline Length of examination & L A & G.A. & L A \% age & G A \% age \\
\hline $0-3$ minutes & 9 & 21 & & \\
$4-6$ minutes & 38 & 44 & $573 \%$ & $762 \%$ \\
$7-9$ minutes & 36 & 34 & & \\
$10-12$ minutes & 29 & 20 & & $238 \%$ \\
13-15 minutes & 22 & 6 & $427 \%$ & \\
More than 15 minutes & 11 & 5 & & \\
\end{tabular}

opposed to local, anaesthesia. Having said this, it is necessary to know whether the longer tme taken to do a bronchoscopy under local anaesthesia is due to the additional care and, consequently, gentleness necessary and whether these cases have fewer sore throats and damaged mouths after operation as a result of this care.

\section{Sore Throats and Damaged Mouths}

Figures for these complications, due to trauma, are shown un Table III. It can be seen that no reduction in trauma resulted from the increased time taken to do the examination under local anaesthesia and, in fact, there was more trauma with this form of anaesthesia. It should be stressed that none of the bronchoscopists using general anaesthesia felt that therr exammation was unduly hasty as a result of any feeling of urgency.

TABLE III

\begin{tabular}{lcc} 
& L A. & GA \\
\hline Sore throats & $122(84 \%)$ & $97(746 \%)$ \\
Sore lips and gums & $10(69 \%)$ & $2(15 \%)$ \\
\hline
\end{tabular}

\section{Efficacy of Local Anaesthesia}

If one accepts the fact that, under general anaesthesia, near perfect operating conditions can be provided-m terms of respiratory quescence-it is pertinent to consider to what extent local anaesthesıa will provide the same facilities. The members of the staff of this hospital used variations on the theme of administration of local anaesthesia Cocaine, Amethocaine, and Xylocaine were all in use. Swabbing of the piriform fossce, using Krause's forceps, dripping local anaesthetic on the glottis from a Nelson s syringe and curved cannula, and injecting local anaesthetic through the crico-thyroid membrane were all used, in various comblnations. Omnopon and Scopolamme was the usual premedication. Luminal was added to this on some occasions. Intravenous Demerol was given, prior to the examination, in some cases where patients appeared inadequately sedated.

Agreeing with Rubin and Kully (10) in their excellent paper on topical anaesthesia for bronchoscopy, the author beheves that variations in technique are of little importance, there being many ways of anaesthetizing a larynx but no substitute for meticulousness with the method of choice. 
The results of the locals given in this series were grouped as follows: (I) Good. This indicated no difficulty in instrumentation, no reflex response, and a quiet patient. (2) Moderate Only the 100 per cent perfect anaesthetic was put into the "Good" group and anything short of that (e.g., one or two bouts of coughing) was termed moderate. (3) Bad. This meant that there was a shambles where the bronchoscopy was only completed with some difficulty (e.g., difficult instrumentation with phonation, coughing, and head moving).

The figures in each group are seen in Table IV. Thus, 87 per cent of cases were reasonably good but the majority were not perfect.

TABLE IV

\begin{tabular}{lll}
\hline \multicolumn{1}{c}{ Efficacy of Local Anaestifesia } \\
\hline Good & $29(20 \%)$ \\
Moderate & $97(669 \%)$ \\
Bad & $16(110 \%)$ \\
Converted to General anaesthesid & $3(21 \%)$ \\
\hline
\end{tabular}

It should be stressed that, broadly speakıng, difficult cases were not moved from the local to the general group and that a higher percentage of good results might have been achieved with local anaesthesia had more time been given to each case. However, it is considered that these figures are representative of the results achieved in the average busy unit, where a serious attempt is being made to obtain efficiency in the limited time available

\section{General Anaesthesia}

It is evident, from the foregoing discussion, that general anaesthesia is preferable with a high percentage of patients and permits a quicker and easier examınation, with less trauma, than is the case with local anaesthesia It is, therefore, necessary to know whether one can recommend its more universal use for this type of endoscopy The answer will depend on whether it produces any other side-effects and whether these are more severe than those produced by local anaesthesia. Complications, not caused by trauma on instrumentation, are shown in Table V.

TABLE $V$

\begin{tabular}{lcc}
\hline Further complications & L A & G A. \\
\hline Postoperative vomiting & $11(7 \% \%)$ & $19(146 \%)$ \\
Headache & $1(07 \%)$ & $3(23 \%)$ \\
Painful eye (corneal abrasion) & 0 & $1(08 \%)$ \\
Peri-venous haeriatoma & 0 & $2(15 \%)$ \\
Cardiac arrest & $1(07 \%)$ & 0 \\
Muscular pain & 0 & $30(231 \%)$ \\
Pulse irregularity & 0 & $26(20 \%)$ \\
Prolonged apnoea (8 minutes) & 0 & $1(08 \%)$ \\
\hline
\end{tabular}




\section{Complications}

It is apparent that, apart from the results of trauma, more complications follow the use of general anaesthesia.

Cardiac arrest. The one case of cardiac arrest was due to a trainee thoracic surgeon being somewhat over-enthusiastic with his dosage of Amethocaine, in a diminutive patient. Interestingly, this patient was one of those given luminal gr. 3 orally, as an anticonvulsant, in addition to Omnopon and Scopolamine. Thiopentone sodium, intravenously, arrested convulsions and permitted intubation. Prompt thoracotomy and cardiac massage were effective and the bronchoscopy was performed a few weeks later, under general anaesthesia. It is felt that, while everyone has a maximum dosage for local anaesthetic agents in mind, there is always someone who, not having seen a toxic reaction, is inclined to be too liberal with the drug, and eventually learns the hard way.

Muscular pains Subcostal pain, following the administration of succinylcholine, was reported and discussed by Currie (11) and others. Since then, this has become recognized as a very frequent occurrence Typically, the day following anaesthesia the patient feels stiff (as though after unaccustomed exercise). This stiffness becomes increasingly painful, reaching a peak that night and passing off by the following night. The aching may affect any part or all of the body. Those affected most are: (1) Those least accustomed to physical exercise: thus, elderly ladies will occasionally be completely incapacitated for 36 to 48 hours; small children are least affected-although none seems immune. (2) Those receiving a bıg dose quickly. It'has been suggested, by Churchill-Davidson (12), that another relaxant will markedly diminush this problem Hegarty (13), in a very recent review of the subject, states that "combining a second depolarizing muscle relaxant with suxamethonium chloride does not increase the incidence of pain and may decrease it." It is the author's opinion that this muxing of relaxants overcomplicates an already thorny subject and is to be deprecated. Early ambulation is sald to increase the mcidence of this complication. ChurchillDavidson (12) quotes 66 per cent incidence in the early ambulants, in his series, and less than one quarter of this in patients confined to bed. It is probable that the figure in the present series is artficially low since the majority were discharged from hospital on the first postoperative day. These would be questioned at about the time of the onset of the symptoms and before, they reached their peak.

Pulse irregularity. Twenty-six patients under general anaesthesia were observed to develop irregularity of the radial pulse, usually preceded by bradycardia. These were reversible exther by the resumption of spontaneous respiration or by artificial ventilation with oxygen. It is of interest that cyanosis was only observed in four of these cases and it is thought that, while anoxia may have played a part, the more significant feature was hypercarbia. E.C.G. records were taken in a few instances but these patients responded with sinus rhythm! This incidence of cardiac irregularity is considered to be of the greatest significance. It is highly probable that the irregularity was due to ventricular extrasystoles Unfortunately, no recommendation can be made as to which cases are likely to show this irregularity. In this group with arrhythmias, the youngest 
patient was twenty-six and the oldest seventy. None had dyspnoea at rest, eight had no dyspnoea, nune had no sputum, and only one was producing more than two ounces dally. The pathology present in these patents was no more severe than in the remainder of the series.

\section{Recovery}

There remains the question of whether the patients given general anaesthesia are as able to look after themselves, immediately after operation, as those under local anaesthesia The advantages of general anaesthesia would be completely offset if they were in increased danger after operation

Of the patients given general anaesthesia, 115 ( $1 \mathrm{e}, 884$ per cent) were awake within five minutes of the end of the examination and able to answer to their name Three were awake within fifteen mmutes, 2 within half an hour, and 10 took longer than this. The 15 patients who did not wake up within five minutes will be analysed

One became anoxic during the bronchoscopy. He had severe chronic bronchitis and emphysema with exertional dyspnoea. This case came early in the series and it is thought that further experience with the technique would have prevented this. Interestingly, the patient's pulse was regular throughout.

Five patients, on arrival in the operating room, were found to be over-sedated on their premedication

Nine patients were given a large dose of thiopentone, m an attempt to ensure there was no possible recollection of the end of the exammation The intention was to reverse this with Megimide (N P 13). However, the latter drug was of no value whatsoever in this respect (as reported elsewhere (14)).

In order to achieve quick awakening at the end of bronchoscopy, and to avold a period of sedation punctuated by coughing and spasm after operation, it is necessary to reduce the induction dose of thiopentone to that which will just abolish the eyelash reflex Approximately $50 \mathrm{mgm}$. succinylcholine is given immediately and the patient is hyperventilated with a high flow of oxygen, after the fasciculations with associated vocal cord adduction have passed. Bronchoscopy is performed with oxygen flowing down the bronchoscope and rhythmical manual compression of the chest is commenced immediately The apex beat or radial pulse must be observed closely Movement is an indication for more succinylcholine, as is the first sign of diaphragmatic excursion-provided the pulse is regular and the colour good Unless the examination is unusually prolonged, no further thiopentone is given.

As might be imagined, a proportion of patients vaguely remember the end of the examination One must accept this if all patients are to awaken quickly after operation. In this series, on direct questioning, 40 patients remembered something ( 30.8 per cent). The majority of these were not sure whether they had been aware of anything or not and said they would not have mentioned it had they not been asked. One dreamed he had his pipe in his mouth' Seven of the 40 considered this experience unpleasant but not sufficiently so to rule out a general anaesthetic on another occasion. None was warned previously that 
this might happen Several proformata were marked, to show which patients might have been awake during the examination, and it was interesting to note that there was little relationship between clinical impression and actual fact! The most purposeful of movements occurred in patients with no recollection of anything.

\section{Possible Improvements on This Method of General Anaesthesia}

A limited trial of the ultra-short-acting barbiturate Baytenal (the sodium salt of 5,5 allyl (2 methyl propyl) thiobarbituric acid) suggests that this type of agent is infinitely preferable to thiopentone sodıum for this type of examination. Deep sedation with rapid recovery occurred consistently and this suggests that one might be able to reduce or abolish the figure of 308 per cent of patients who remember something of the examination, without lengthening the awakening time

A short-acting relaxant of the competitive type might permit some degree of spontaneous respuration Frestonal has been reported upon. The author has no experience of this drug but understands that it is probably not the answer to this problem Certainly, a technique using spontaneous respiration but permitting immediate postoperative consciousness and an active cough reflex should be the aim.

Many workers use Currass type respirators on patients who appear to be poor risks The dufficulty of selectıng the poor risks (from the carduac irregularity standpoint) has been mentioned and the inefficiency of this type of respirator on those with a fixed thoracic cáge is well known.

\section{Contraindications}

Many anaesthetists believe that there are few contraindications to general anaesthesia. Certainly, as it exists today, it is unsuitable for those with myocardial ischaemia, gross anaemia, and empyemata with bronchopleural fistulae. Decompensated heart disease and orthopnoea are further contrandications Pregnancy is a possible contraindication.

Although three epileptics were given local anaesthesia in this series, without mishap, it is thought that these and the one psychatric case included should have had general anaesthesıa.

One would conclude by sayıng that local anaesthesia is contraindicated for the patient who desires to be asleep and who has good cardio-respiratory function.

\section{SUMMARY}

Some of the advantages and disadvantages of local and general anaesthesia for bronchoscopy have been discussed and the findings in a series of 275 cases reported. It is shown that general anaesthesia is preferable to a high percentage of patients, permitting an easier instrumentation and quicker examination and giving fewer complications of trauma, but the present technique, using succinylcholne and thopentone, introduces several further complications, figures for which are given. It is suggested that, while each case should be considered on 
its merits, general anaesthesia will be the anaesthesia of choice in the vast majority of cases. Suggestions are made for improvements in the current technique.

\section{ACKNOWLEDGEMENTS}

I should like to express my thanks to the various members of the consultant and registrar staff of the Brompton Hospital who look an active interest in this problem and who assisted in the collection of data.

\section{RÉSUMÉ}

275 anesthésies pour bronchoscopie pour fin de diagnostic servent de matière pour comparer les avantages et les désavantages de l'anesthésie locale et de l’anesthésie générale.

Le problème est abordé comme suit:

1. Une misse au point des conditions anesthésiques idéales pour la bronchoscopie. Dans le détail, on a tenu compte des considérants suivants: (a) Les meilleures conditions d'opération: ce qui devrait être le but de chacun; (b) L'importance' du risque pour le malade. (c) L'acceptation de l'anesthésie locale par le malade. 47 pour cent de ceux à on avait fait une anesthésie locale opteraient pour une générale s'ils devaient avoir une autre bronchoscopie, 0.8 pour cent de ceux à qui on a fait une générale préféresaient une anesthésie locale si la chose était à recommencer.

2. Un rapport et une appréciation du degré de succès ou du manque de succès obtenu dans la séne présentée soit sous anesthésie locale soit sous anesthésie générale. Des groupes comparables de malades ont été soumis, les uns à l'anesthésie locale, les autres à l'anesthésie générale; l'mstrumentation dans le premier groupe a été plus difficile. L'examen a été fait en moins de temps et avec moins de traumatisme sous anesthésis générale.

Dans le groupe de malades examinés sous anesthésie locale, on a qualifié les résultats de bons, passables ou mauvais; 87 pour cent des cas sont entrés dans les deux premières classifications, mais seulement 20 pour cent des résultats étaient parfaits.

On présente des statistiques sur les vomissements postopératoires, la céphalée, les douleurs musculaires, les irrégularités du pouls, etc.; en ce qur concerne ces complications, les statistiques montrent que l’anesthésie générale en entraîne davantage; certaines de ces complications sont étudiées plus particulièrement.

Chez tous les cas soumis à l'anesthésie générale, on a noté le temps écoulé depuis la fin de l'examen au moment où le malade pouvait répondre à son appel. Dans la grande majorité des cas, cet espace de temps a été inférieur à cinq minutes.

3. On a étudié les améliorations possibles de la technique habituelle avec l'anesthésie générale si l'on emploie la succinylcholine et le thiopentone. Les contrindications sont énumérées.

A tout considéré, nous sommes d'avis que, bien que chacun des malades doit être étudié et pose son problème, l'anesthésie générale sera choisie dans la plupart des cas. Les techniques actuelles ne sont toutefois pas parfaites. 


\section{REFERENCES}

1. Thomas, Dylwyn. Personal communication.

2 D'ABreu. Textbook of Thoracic Surgery.

3. Jooste, K H Anaesthesia 1054 (1955).

4. Cheatle, C A \& Chambers, K. B Anaesthesia 1J. 171 (1955)

5. Kelsall, P D. Bnt. J Anaes. 26: 182 (1954)

6. Churchill-Davidson, H C. Anaesthesia 7: 237 (1952).

7. Clafk, J V. \& Goodwin, G. P. J Laryng. \& Otol. 64: 570 (1950).

8. Herron, R A C. Anaesthesia 5. 40 (1950).

9. Churchiml-Davmson, H C Anaesthesia 8. 128 (1953)

10 RuBin, H. J \& KuLLY, B M Arch. Otolaryng. 56. 13 (1952)

11 Currie, T T. Bnt M. J 1 10:32 (1953)

12 Churchill-Davmson, H C. Brit M. J 174 (1954).

13 Fatrley, H Barrie Can. M. A J 73914 (1955)

The Canadian Anaesthetısts' Society wishes to repurchase a limited number of copies of the January, Aprl, and July, 1955, and January 1956 issues of the Journal, at $\$ 100$ per copy. Copres must be complete and unmarked, and should be forwarded to The Secretary, Canadian Anaesthetısts' Society, 516 Medical Arts Bulding, Toronto 5, Ontarı 